\title{
An Empirical Examination of Supply Chain Sustainability in Turkish Automotive Sector: Using the PLS-SEM Approach
}

\author{
Sefer Burak Kacar ${ }^{1}$, Bülent Sezen ${ }^{1}$, Hakan Kitapç ${ }^{1}$ \\ ${ }^{1}$ Department of Business Administration, Gebze Technical University, Turkey \\ Correspondence: Sefer Burak Kacar, Department of Business Administration, Gebze Technical University, \\ Turkey.
}

Received: October 31, 2017

Accepted: November 29, 2017

Online Published: December 1, 2017

doi:10.5539/ibr.v11n1p44

URL: https://doi.org/10.5539/ibr.v11n1p44

\begin{abstract}
In today's dynamic environment, it has become a necessity for firms to better control their supply chain operations against supply chain vulnerabilities. Little consideration has been paid to the relationship between business environment, supply chain risks, supply chain vulnerability, supply chain performance and sustainability. Hence, we aim with this study to unveil the influence of supply chain variables on supply chain performance and sustainability. The proposed model consists of 10 hypotheses to disclose the relationship between 6 main constructs; Supply Chain Uncertainty, Supply Chain Risks, Supply Chain Performance, Collaborative Planning Systems, Vulnerability, and Supply Chain Sustainability. The hypotheses are validated by empirical study with 213 domestic and foreign automotive companies operating in Turkey. The results of this study indicate that supply chain sustainability is primarily affected by supply chain performance and collaborative planning systems. The findings of this study could provide the necessary point of view for the managers working in supply chain management area to comprehend the dynamics behind sustainable supply chains.
\end{abstract}

Keywords: structural equation modelling, supply chain performance, supply chain risks, supply chain sustainability, uncertainty

\section{Introduction}

Supply Chain Management is a complicated field, which is a primary factor of success or failure of many organizations. According to Kumar and Nambirajan (2014, pp. 67), many manufacturing enterprises are structured in order to maximize the output and lower their cost by giving little attention to inventory levels and distribution capabilities. The term supply chain management (SCM) came to the forefront in the last two decades (Cooper et. al., 1997). In order to stay competitive, companies should mitigate Supply Chain Risks and also eliminate Supply Chain Vulnerabilities they are subject to. Enterprises should establish a strategic approach in order to stay in business (Monczka, Trent, and Handfield, 1998). Literature has focused on the need to understand supply chain practices (SCPs), which is mandatory for staying in the competitive global market and grow consistently and profitably (Power et. al., 2001). For instance, one of the widely adopted SCM practice 'Collaborative Planning' is proactive and cooperative activity that promote customer service for the purpose of obtaining comparative advantage for supply chain members as well as the supply chain as a whole. As Christopher (1992) has stated 'the supply chains of the enterprises compete with each other rather than the companies from now on'. The main purpose of this article is to explore the antecedents of the supply chain performance, collaborative planning system and supply chain vulnerability and their total impact on supply chain sustainability. Although numerous earlier papers have tested for factors affecting supply chain performance by considering mostly supply chain strategies ( $\mathrm{Li}$ et. al., 2006; Vanichchinchai A. and Igel B., 2011), there are limited studies considering the impacts of supply chain vulnerability on supply chain sustainability.

Furthermore, in the literature, the concept of vulnerability still needs to be illuminated and conceptualization of the concept is still missing. Hence, its meaning is still ambiguous and ill-defined (Svensson, 2000). In his study, he defined vulnerability as the existence of random disturbances causing deviations in the supply chain of components and materials from normal, expected or planned schedules or activities, which have a negative impact on manufacturers or on their subcontractors. Since modern supply chains are becoming more complicated and interrelated at a faster pace, it is tough to guess the type and nature of uncertain developments 
or the impact of any action (Helbing et. al., 2006). The concept of sustainability is gradually acknowledged as an effective policy to cope with some of the today's challenges facing global supply chains. It results in boosting competitiveness and improved financial performance (Wang and Sarkis, 2013). Therefore, the study by Wang and Sarkis (2013) focuses on supply chain sustainability since cost reduction is increasingly regarded as the origin of supply chain sustainability and vital for the long-term profitability of an enterprise.

Even though some organizations have comprehended the significance of supply chain sustainability, they often do not know exactly which factors impact sustainability. This study aims also to reveal factors affecting supply chain sustainability and supply chain performance and also their interactions between them and hence to fill a gap in supply chain management literature. The sample of this study consists of 213 of the biggest domestic and foreign automotive firms operating in Turkey. Instead of taking companies as independent units, this approach will evaluate firms' performances extensively in relation to supply chain vulnerability.

The article continues in the following manner. In the first section, we briefly present the literature comprising supply chain management (SCM), uncertainty, supply chain risks (SCR), supply chain performance (SCP), collaborative planning systems, supply chain vulnerability, and supply chain sustainability, respectively.

Afterwards, the hypotheses are tested through the data collected from 213 companies in automotive sector operating in Turkey. The data collection and method of analysis are elucidated thoroughly. Finally, in the last part, the research findings are introduced and discussed with managerial implications.

\section{Literature Review, Hypotheses and the Research Model}

In this section, the constructs used in our research model will be defined in detail and interrelations of these constructs will be explored.

\subsection{Uncertainty}

Trkman and McCormack (2009) has put forward that an important division of risks, namely the origin of risks which can either be within a chain or from the outer environment has been neglected in earlier research. The authors have distinguished between the different kinds of risks based on the sources of uncertainty, namely endogenous uncertainty and exogenous uncertainty.

Endogenous uncertainty: This source is intrinsic to SC and can result in changing focal firm and suppliers. Market and technology turbulence are the most outstanding among them.

Exogenous uncertainty: The source of uncertainty/risk originates from outside of the SC. The authors have proposed to divide these risks into the two most remarkable kinds. These are: discrete events (e.g. terrorist attacks, contagious diseases, workers' strikes) and continuous risks (e.g. inflation rate, consumer price index changes).

Few studies in the literature have analyzed the relationship between flexibility, uncertainty, and performance for manufacturing systems in detail (Merschmann, and Thonemann, 2011). However, in our study, we analyze the direct impact of uncertainty on supply chain performance. As in most studies in the literature, we expect that supply chain performance is negatively influenced with an increase in uncertainty.

In this study, survey questions regarding uncertainty have been adapted from the studies by Cannon and Homburg (2001) and Inman et al. (2011). Hence, we propose that:

$\mathbf{H}_{\mathbf{1 a}}$. The level of uncertainty will have a significant influence on supply chain performance.

$\mathbf{H}_{\mathbf{1 b}}$. The level of uncertainty will have a significant influence on collaborative planning systems.

$\mathbf{H}_{\mathbf{1 c}}$. The level of environmental uncertainty will have a significant influence on supply chain vulnerability.

\subsection{Supply Chain Risks}

Risk form the consumer's point of view can be defined as the uncertainty and adverse consequences of buying a product or service (Dowling and Staelin, 1994). Risk sources are the environmental, organizational or supply chain related variables that cannot be predicted with accuracy and that affect the supply chain-outcome variables. Supply Chain Risk Management can be defined as the management of SC risks through co-ordination or collaboration among the SC partners in order to guarantee profitability and continuity (Tang, 2006). Risk management process is concentrated on understanding the risks, and minimizing their impact (Faisal, 2006). The phases of the risk management process diversify from risk identification/analysis (or estimation) via risk assessment (or evaluation) to different ways of risk management (Norrman and Jansson, 2004). Vendor and supplier rating programs, contingency programs or early warning systems can be cited among the elements of risk identification. On the other hand, risk mitigation encompasses practices such as rethinking and re-evaluating 
their supply and distribution strategy (for instance, by using postponement and changing the loc ation of some facilities, etc.) and supplier development (Manuj and Mentzer, 2008; Blome and Schoenherr, 2011).

Supply Chain Risk Management encompasses various fields such as operations management, marketing, finance and strategy with different points of views working together (Bandaly et. al., 2012). Bandaly et. al.'s study reviewed risks in supply chains, supply chain vulnerabilities, supply chain structure and selection of risk management approaches. Likewise, Stauffer (2003) has put forward that the nature of risk could diversify (i.e. political instability, exchange rates, carriage capacity, shelf life, and customer demand). The author has also asserted that although these risks are not new, supply chain managers always keep the dangers related with these risks in mind. Wieland and Wallenburg (2012) has supported the view that supply chain strategies and SCRM for the purpose of managing risk by diminishing the vulnerability and ensuring continuity can be seen as being a “two-sided coin"(Wieland and Wallenburg, 2012, pp. 888). The authors demonstrated empirically that both proactive (i.e. robust) and reactive (i.e. agile) supply chain strategies lead to reduction of the vulnerability of global supply chains and are in that sense necessary. Christopher and Peck (2004) divided supply chain risks as external and internal risks, which is a similar to the study conducted by Thun and Hoenig (2011). Thun and Hoenig (2011) have examined supply chain risk management in the German automotive industry empirically. The study conducts a survey with 67 manufacturing plants in the German automotive industry. The vulnerability of supply chains has been investigated and supply chain risks have been identified by analyzing their likelihood to occur and their potential impact on the supply chain. The trend towards lean supply chains results in low inventories, but leads to high inventories due to the turbulences without safety stocks. Various authors have identified different supply chain risks and these studies revealed the need for an empirical work in supply chain risk management. It is obvious that more research should be conducted in order to find out the instruments for an effective supply chain risk management. While internal company risks consider mainly the disruptions caused by problems within the organizational boundaries of the company such as machine breakdowns or IT problems, the main attention of the external supply chain risks is environmental causes that lead directly or indirectly to disturbances within the supply chain. These environmental causes can be sociopolitical, economical, technological or geographical reasons.

Cucchiella and Gastaldi (2006) have divided supply chain risks into categories of internal (involving such issues as capacity variations, regulations, information delays, and organizational factors) and external (market prices, actions of competitors, manufacturing and yield costs, supplier quality, and political issues). Risk is also a function of the level of uncertainty and the impact of an event. Many sources contribute to uncertainty in a supply chain (Sinha et. al., 2004). Typical supply chain risks involve disruptions and delays caused by supply risks such supply capacity constraints, quality issues, supplier liquidity problems, supplier dependency, product design changes, delivery delays (Chopra and Sodhi, 2004), procurement related risks such as exchange rates, inventories and stockouts (Hallikas et al., 2002), logistics and transportation risks (Wu and Blackhurst, 2009), supply chain relational risks such as hold up risks and moral hazard (Zsidisin et al., 2004), demand risks such as demand volatility and inaccurate forecasts, information distortion and stock accumulation due to the bullwhip effect (Sinha et al., 2004), and infrastructure and systems risks such as breakdowns, equipment malfunctions (Zsidisin et al., 2004).

In a study by Wagner and Bode (2008), five different supply chain risk sources have been classified. These could be cited as: (1) demand side; (2) supply side; (3) regulatory, legal and bureaucratic; (4) infrastructure; and (5) catastrophic. As indicated by the authors, while, the first two risk categories manage supply-demand coordination risks that are internal to the supply chain, the last three concentrate on risk sources that are not really inside the supply chain.

In this study, we endeavor to respond three important research questions regarding supply chain risks: How does SCRs influence supply chain performance? Are SCRs related to collaborative planning systems? What is the relationship between SCRs and supply chain vulnerability?

This study makes a contribution to the literature from two points of view. First, this study is among the first ones that examine the impact of SCRs on collaborative planning systems empirically. Second, this study attempts to examine the relationship between two close constructs, i.e. SCRs and vulnerability. Moreover, the findings of this study provide managerial implications for manufacturing companies worldwide.

Survey questions excluding the third one, which is added by the authors, regarding supply chain risks has been adapted from the study by Wagner and Bode (2008). Hence, we propose that:

$\mathbf{H}_{\mathbf{2} \mathbf{a}}$. The level of supply chain risks will have a significant influence on supply chain performance.

$\mathbf{H}_{2 \mathbf{b}}$. The level of supply chain risks will have a significant influence on collaborative planning systems. 
$\mathbf{H}_{\mathbf{2 c}}$. The level of supply chain risks will have a significant influence on supply chain vulnerability.

\subsection{Supply Chain Performance}

Numerous studies in literature explored the factors which have impact on supply chain performance. Most of them concentered on the relationship between supply chain strategies and performance. Two different supply chain management strategies can be cited as: (1) risk and (2) opportunities, which are influenced by different intentions (assess and reduce risks vs increase and realize opportunities) (Schaltegger and Burritt, 2014, pp.234). Wieland and Wallenburg (2012) revealed empirically that both proactive (i.e. robust) and reactive (i.e. agile) supply chain strategies are essential for lessening of the vulnerability in global supply chains. The research by the authors has provided strong support for the assumption that both agility and robustness strategies may be important in improving the supply chain's customer value and business performance. Bavarsad et. al. (2013) attempted to reveal the relationship between supply chain management strategy with logistics performance and organizational performance (marketing and financial). The authors have considered supply chain management strategy based on universality and integration, i.e, their organizational performance (marketing and financial) will be increased with implementing this strategy in production organizations. In order to measure logistics performance five criteria, namely, delivery speed, delivery flexibility, order full capacity, responsiveness, and delivery dependability, have been utilized. Moreover, average market share growth, average sales volume growth and average sales (in dollars) growth are used for the evaluation of marketing performance in comparison with other rivals of the industry. Return on sales, profit growth and average profit and return on investment in comparison with the rivals are used for the evaluation of financial performance. Another study conducted by Qrunfleh and Tarafdar (2012) have examined the relationship between supply chain (SC) strategy and supply chain information systems (IS) strategy, and its impact on supply chain performance and firm performance. The authors support the argument by Gunasekaran and Ngai (2004) proposing that 'to successfully managing the supply chain lies in measuring and monitoring information about its key operational and performance parameters (e.g. inventory, delivery schedules and lead times)'. Inman et. al. (2011) conducted a study to develop and test a structural model incorporating agile manufacturing as the focal construct. This model includes the primary components of JIT (JIT-purchasing and JIT-production) as antecedents. Operational performance and firm performance are measured as a consequence of JIT strategy. Survey questions regarding supply chain performance has been adapted from the study by Kim (2009). In our study, we propose that:

$\mathbf{H}_{3}$. The level of supply chain performance will have a positive influence on supply chain sustainability.

\subsection{Collaborative Planning Systems}

Construct of collaborative planning systems encompasses survey questions regarding information sharing, collaborative planning systems, supply network structure, and distribution network structure. As has been stated in the study by Kocoglu et. al. (2011): 'Information sharing essentially contributes in diminishing supply chain costs, enhancing partner relationships, expanding material flow, enabling faster delivery, improving order fulfillment rate and hence contributing to customer satisfaction, enhancing channel coordination, and enabling the success of competitive advantage". Li et. al. (2006) analyzed the effect of supply chain management practices on competitive advantage and organizational performance. The research has devised five dimensions of SCM practice (strategic supplier partnership, customer relationship, level of information sharing, quality of information sharing, and postponement) and has tested the relationships between SCM practices, competitive advantage, and organizational performance. The elements of SCM in the study by Mentzer et. al. (2001) could be cited as agreed vision \& goals, agreed supply chain leadership, information sharing, long-term relationship, risk $\&$ reward sharing, process integration, and cooperation. In our study, information sharing, collaborative planning systems, supply network structure and distribution network structure has been gathered under a single roof, i.e. collaborative planning systems. Survey questions regarding collaborative planning systems has been adapted from the studies by Cook and Heiser (2010) and Chen and Paulraj (2004). Thus, in our study, we propose that:

$\mathbf{H}_{\mathbf{4}}$. The level of collaborative planning systems will have a positive influence on supply chain performance.

$\mathbf{H}_{5}$. The level of collaborative planning systems will have a positive influence on supply chain sustainability.

\subsection{Supply Chain Vulnerability}

Supply chain vulnerability term can be conceptualized as an exposure to serious disturbance, originating from both internal and external supply chain risks (Christopher and Peck, 2004, p. 3). Several publications refer to how certain supply chain characteristics might increase or decrease the vulnerability of the supply chain. Jüttner (2005) has stressed that the identification and management of risks for the supply chain, through a coordinated approach amongst supply chain members, to reduce supply chain vulnerability as a whole. The author come up 
with the finding that 44 per cent of all eight responding companies in his study expect the vulnerability of their supply chains to increase in the next five years. Wagner and Bode (2006) have found assumptions in the literature that supply chain vulnerability is increased by customer dependence, supplier dependence, supplier concentration, single sourcing, and global sourcing. Moreover, the survey questions regarding the supply chain vulnerability has been adapted from the study by Thun and Hoenig (2011). The authors have examined supply chain risk management in the German automotive industry empirically. The analysis is based on a survey with 67 manufacturing plants in the German automotive industry. The vulnerability of supply chains has been investigated and supply chain risks have been identified by analyzing their likelihood to occur and their potential impact on the supply chain. Based on empirical results they deduce that supply chains are mostly thought of being vulnerable. A probable reason for that is linked to be low implementation level of the instruments of the supply chain risk management which is in compliance with the literature (Jüttner, 2005; Tang, 2006b). Moreover, factors increasing complexity such as globalization and product variants on the one hand, and factors increasing efficiency such as outsourcing or reduction of suppliers on the other hand are identified as key developments driving supply chain risks and hence increasing supply chain vulnerability. Globalization brings about supply chain risk since the resulting dependencies might lead to risks both on the demand and supply side. In addition to that, the ongoing trend towards offshoring will also rise the vulnerability of supply chains due to the complexity of supply relationships and susceptibility to faults owing to cross-national connections. Survey questions regarding supply chain vulnerability has been adapted from the study by Thun and Hoenig (2011).

In our study, we propose that:

$\mathbf{H}_{6}$. The level of supply chain vulnerability will have a significant influence on supply chain sustainability.

\subsection{Supply Chain Sustainability}

Sustainability has been defined by Carter and Rogers (2008, pp. 368) as 'the strategic, transparent integration and achievement of an organization's social, environmental, and economic goals in the systemic coordination of key interorganizational business processes for improving the long-term economic performance of the individual company and its supply chains'. Sustainability can also be considered as the degree to which present decisions of organizations impact on the future situation of the natural environment, societies and business viability (Krysiak, 2009). As has been stated in the study by Schaltegger and Burritt (2014), the objective of sustainability performance management has initially served for the identification of social and environmental deficiencies and risks in the supply chain and therefore is a foundation for improved risk management. Sustainability management and action involves consideration of environmental factors and social aspects of organizational activities, as well as their integration with conventional economic performance (Seuring and Müller, 2008). Cheung and Rowlinson (2011) have examined, by means of case studies, the mechanisms by which relationships can be managed and by which communication and cooperation can be enhanced in sustainable supply chains. The research has adopted a triangulated approach in which quantitative data were collected by questionnaire, interviews were conducted to explore and enrich the quantitative data and case studies were undertaken in order to illustrate and validate the findings. The development of a sustainable supply chain has been seen by the authors to depend, in part, on the transfer of knowledge and capabilities from these larger players down the chain. From the point view of the authors, if a firm is to maintain a competitive advantage and its sustainability, it needs to develop core competences which are capable of being developed further over time in response to both environments and internal resources. The works of Carter and Easton (2011) have aimed to conduct a systematic review of sustainable supply chain management (SSCM) literature in the principal logistics and supply chain management journals, across a 20 year time frame. The authors have suggested that the broad concept of sustainability, and the key interfaces that sustainability has with supply chain management, strongly suggests that sustainability is instead license to do business in the twenty-first century and supply chain management is an integral component of this license.

Although, in the literature, there are limited number of studies that take into account of both supply chain risks and sustainability in a conceptual model, adding one more construct i.e. supply chain vulnerability to our conceptual model will illuminate the mechanism behind supply chain performance more precisely. Furthermore, unveiling of the elements of sustainability could serve to manage and also to mitigate sustainability related risks as well. In that sense, this study tries to combine constructs affecting supply chain sustainability in the literature as well.

Another survey related with sustainable supply chain management has been conducted by Zailani (2012) among 400 manufacturing firms in Malaysia. Factor analysis of the survey has revealed that four categories of outcomes (environmental, economic, social and operational) have decomposed. Survey questions regarding supply chain 
sustainability has been adapted from the study by Zailani (2012).

Figure 1 presents a framework displaying the relationship between Uncertainty, Supply Chain Risks, Supply Chain Vulnerability, Collaborative Planning Systems, Supply Chain Sustainability, and Supply Chain Performance. The research herein, empirically tests the linkages between 6 main constructs. The dimensions of supply chain performance can be cited as financial performance and market based performance. In our research model, the dimensions of supply chain sustainability are represented by economic sustainability and operational sustainability. Furthermore, while the dimensions of collaborative planning systems can be cited as information sharing, collaborative planning systems, supply network structure and distribution network structure, the dimensions for supply chain risks are represented by regulatory, legal and bureaucratic risk, infrastructural risks, catastrophic risks, and supply side risks. Uncertainty and supply chain vulnerability consist of only one dimension in our conceptual model.

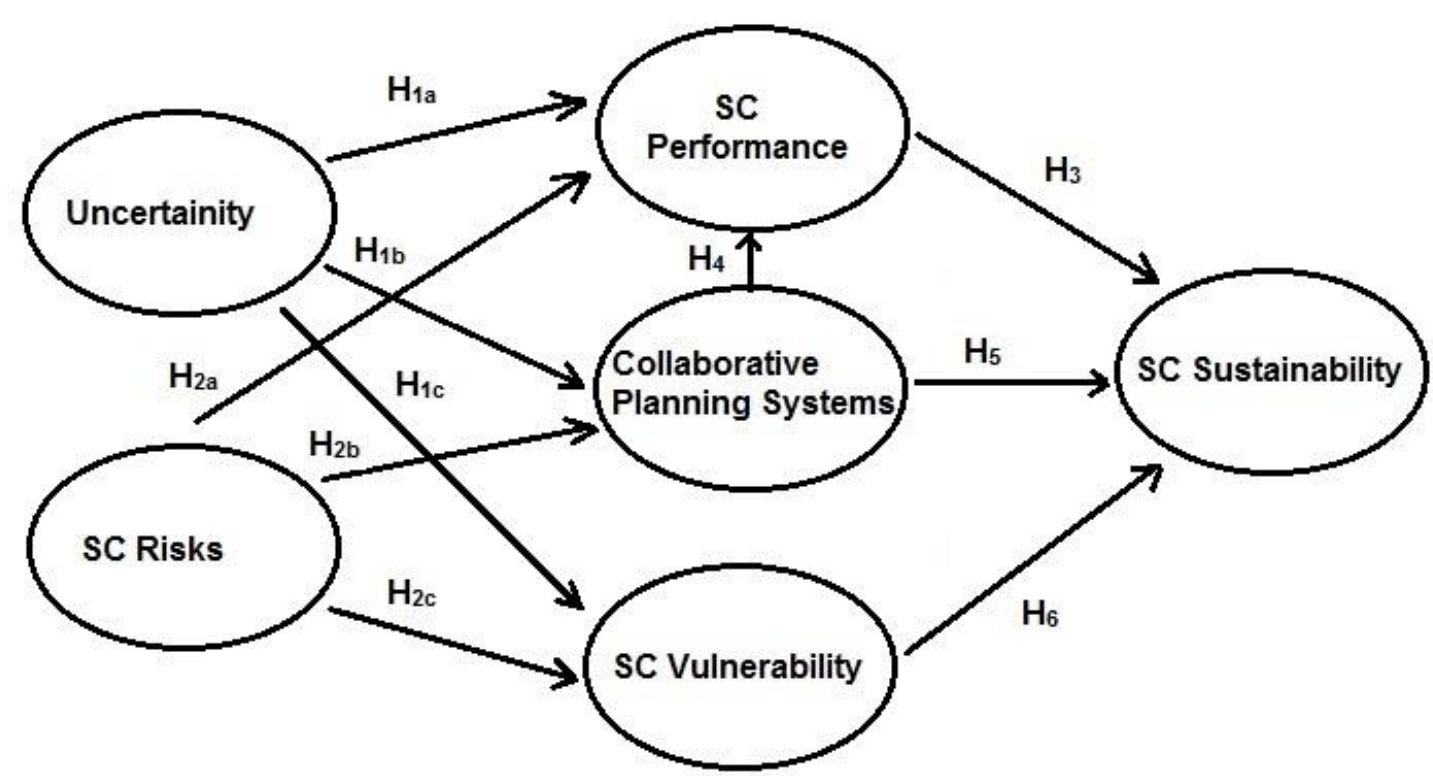

Figure 1. Conceptual Model

\section{Research Methodology}

\subsection{Sampling and Data Collection}

In order to explore empirically what the main supply chain performance drivers are and what the impact of supply chain performance and two more constructs are on the sustainability of companies in automotive sector, a questionnaire was developed and a survey was conducted in years 2015/2016 within a period of 6 months. The survey included 41 individual questions designed to assess uncertainty, supply chain risks, supply chain performance, collaborative planning systems, supply chain vulnerability and supply chain sustainability. The initial survey draft was discussed with firms' executives and it was pre-tested by 10 pilot interviews to ensure that the wording, format and sequencing of questions were appropriate. The reason for selecting automotive sector lies in the accessibility of the data and the intensity of the utilization of supply chain in automotive sector. The data have been collected mainly from Tuzla Organized Industrial Zone of Automotive Subsidiary Industry (TOSB), Association of Automotive Parts\&Components Manufacturers (TAYSAD), Istanbul Chamber of Industry (ICI) and Uludag Automotive Industry Exporters'Association(OIB).

The questionnaire was applied simultaneously through online surveys and face-to-face interviews to the sample. The respondents who deal with supply chain management were asked to complete the questionnaire.

First, a web-based survey at site www.surveey.com has been developed in order to facilitate data collection and also to enable data transfer from website to SPSS or Excel file format to process data. In order to collect data, a contract has been signed with a survey company within a frame of a grant of Scientific Research Project.

\subsection{Pilot Study}

Primarily, we have selected Turkish automotive sector as our focus sector. We have informed the survey company 
collecting data on behalf of us that they have to interrupt the data collection before attaining 50 questionnaires. In a period of one month, we gathered 48 questionnaires and conducted the pilot study. Since the scales were used with a new sample, the items were subjected to exploratory factor analysis with SPSS 22.00. The best fit of data was obtained with a principal component analysis utilizing Varimax rotation with Eigenvalues of 1 as a cut of point. In the data reduction procedure, those items having a factor loading of lower than 0.50 and those having collinearity with more than one factor, were removed one by one while continuing the factor analysis until reaching the ideal factor table. The variables have been divided into two categories: exogenous and endogenous variables. Factor loading for exogenous values are found out between 0,50 and 0,94 , with a total variance explained $81.17 \%$. Furthermore, the Kaiser-Meyer-Olkin test which informs the researchers about the adequacy level of the scales has been found as $\mathrm{KMO}=0.56$. Yet, factor loading for endogenous values have been found between 0,54 and 0,94, with a total variance explained 75,8\%. Moreover, the Kaiser-Meyer-Olkin adequacy test result has suggested that the sample was factorable $(\mathrm{KMO}=.689)$.

\subsection{Common Method Variance}

Common method variance (CMV) is controversial in quantitative studies and any self-report survey (Spector, 2006), as it threatens the validity of the findings on the linkage results between constructs (Reio, 2010; Williams and Brown, 1994). CMV is "variance that is attributable to the measurement method rather than to the constructs the measures represent" (Podsakoff, MacKenzie, Lee, \& Podsakoff, 2003: 879). CMV creates a false internal consistency, that is, an apparent correlation among variables generated by their common source. Podsakoff et al. (2003) explore four general sources of CMV: the use of a common rater, the manner in which items are presented to respondents, the context in which items on a questionnaire are placed, and the contextual influences (time, location and media) used to measure the constructs. According to Reio (2010), procedural design and statistical control are two solutions to reduce the probability of CMV. Following Podsakoff et al. (2003), this study addressed the CMV issue at the questionnaire design stage (common rate effects, acquiescence biases (yea- saying and nay-saying), item characteristic effects, common scale formats, item priming effects and scale length were avoided throughout the questionnaire). Secondly, a statistical technique, i.e. Harman's one-factor test was conducted. Therefore, the statistical results demonstrate that $\mathrm{CMV}$ is not a concern in this study.

\subsection{Non-response Bias}

Non-response bias has been thought as a "serious concern" and should be tackled by researchers (Etter and Perneger, 1997; Lewis et al., 2013; Rezaei and Ghodsi, 2014), especially in electronic surveys (Menachemi, 2010). "Response bias occurs when individuals who respond to a survey differ systematically from those that were invited to participate but did not respond" (Menachemi, 2010, p. 5) in which "the participants do not represent non-participants" (Thompson et al., 2014). Methods to adjust for nonparticipation are complicated and the impact of nonparticipation on the total sample is difficult to evaluate since researchers seldom have knowledge about nonparticipants (Lin and Schaeffer, 1995). In our research model, we did ignore the impact of non-response bias since the sample has been collected from white collar professionals and the data mainly consist of face to face data and the rest is online survey with compulsory fields.

\subsection{Validity and Reliability}

Validity analysis consist of content validity and construct validity. All measurement items expect a few in this survey are taken directly from existing literatures; hence, they have a good content validity. Convergent validity can be evaluated from the measurement model by determining whether each indicator's estimated pattern coefficient on its hypothesized underlying construct factor is significant (Anderson and Gerbing, 1988). As shown in Table 1 , all normalized pattern loadings are statistically significant $(\mathrm{p}<0.01)$, therefore convergent validity was demonstrated. Reflective scales were utilized in this study in order to calculate the reliabilities. (Kleijnen et. al., 2007). In order to evaluate the psychometric features of measurement instruments, a null model, with which there is no structural relation, was utilized. To calculate reliability, a Chronbach's alpha, composite reliability (CR) and the average variance extracted (AVE) were utilized. Internal consistency is demonstrated when the reliability of each measure in a scale is above 0.7 (Brown, 2006; Kline, 2011). Cronbach's alpha and composite reliability values explain over the threshold value of 0.7 as recommended by Nunnally and Bernstein (1994). As it is demonstrated in Table 1, the measurement model provided enough evidence for internal consistency. Convergent validity has been established by the examination of factor analysis results displayed in Table 1. Each manifest variables (MV) are loaded above to the related latent variables (LV). Convergent validity is also ensured when the average variance extracted (AVE) is higher than 0.5 (Hair et. al., 2011). Except for the latent variables Supply Chain Risks and Collaborative Planning Systems, convergent validity has been assured. 
Table 1. Measurement model results

\begin{tabular}{|c|c|c|c|c|c|c|c|}
\hline & $\begin{array}{l}\text { Factor } \\
\text { loadings }\end{array}$ & $\begin{array}{l}\text { Indicator } \\
\text { Weights }\end{array}$ & Mean & $\begin{array}{l}\text { Std. } \\
\text { Dev. }\end{array}$ & $\begin{array}{l}\text { Cronbach } \\
\text { Alpha }\end{array}$ & $\begin{array}{l}\text { Composite } \\
\text { Reliability }\end{array}$ & AVE \\
\hline $\begin{array}{l}\text { Environmental } \\
\text { Uncertainty }\end{array}$ & & & 3.62 & 1.92 & 0.748 & 0.857 & 0.67 \\
\hline Envunc1 & 0.986 & 0.418 & 3.36 & 1.80 & & & \\
\hline Envunc2 & 0.994 & 0.439 & 3.69 & 1.90 & & & \\
\hline Envunc3 & 0.950 & 0.363 & 3.81 & 2.03 & & & \\
\hline Supply Chain Risks & & & 3.31 & 2.14 & 0.806 & 0.849 & 0.35 \\
\hline Legist1 & 0.930 & 0.185 & 3.93 & 2.05 & & & \\
\hline Legist2 & 0.875 & 0.171 & 4.08 & 2.16 & & & \\
\hline Legist3 & 0.960 & 0.186 & 4.18 & 2.06 & & & \\
\hline Infrstr1 & 0.911 & 0.164 & 2.72 & 1.97 & & & \\
\hline Infrstr2 & 0.924 & 0.175 & 3.54 & 2.16 & & & \\
\hline Infrstr3 & 0.915 & 0.171 & 4.15 & 2.07 & & & \\
\hline Infrstr4 & 0.925 & 0.161 & 4.46 & 2.01 & & & \\
\hline Ctsrisk2 & 0.707 & 0.104 & 1.70 & 1.29 & & & \\
\hline Ctsrisk3 & 0.735 & 0.114 & 1.83 & 1.46 & & & \\
\hline Ctsrisk4 & 0.712 & 0.115 & 2.41 & 2.01 & & & \\
\hline Suprisk5 & 0.675 & 0.118 & 3.37 & 1.75 & & & \\
\hline $\begin{array}{l}\text { Supply } \\
\text { Vulnerability }\end{array}$ & & & 4.36 & 1.74 & 0.844 & 0.882 & 0.52 \\
\hline Supvull & 0.939 & 0.211 & 4.92 & 1.61 & & & \\
\hline Supvul2 & 0.967 & 0.215 & 4.45 & 1.59 & & & \\
\hline Supvul3 & 0.916 & 0.184 & 3.99 & 1.69 & & & \\
\hline Supvul4 & 0.974 & 0.201 & 4.66 & 1.76 & & & \\
\hline Supvul7 & 0.889 & 0.189 & 3.86 & 1.67 & & & \\
\hline Supvul8 & 0.922 & 0.198 & 4.39 & 1.80 & & & \\
\hline Supvul9 & 0.982 & 0.189 & 4.28 & 1.84 & & & \\
\hline $\begin{array}{l}\text { Collaborative Planning } \\
\text { Systems }\end{array}$ & & & 4.37 & 1.98 & 0.871 & 0.896 & 0.42 \\
\hline Infosh1 & 0.928 & 0.087 & 4.68 & 1.96 & & & \\
\hline Infosh2 & 0.920 & 0.102 & 5.28 & 1.66 & & & \\
\hline Colpsys3 & 0.991 & 0.155 & 4.32 & 1.86 & & & \\
\hline Colpsys4 & 0.974 & 0.147 & 4.02 & 1.89 & & & \\
\hline Colpsys 5 & 0.992 & 0.156 & 4.39 & 1.74 & & & \\
\hline Colpsys6 & 0.957 & 0.134 & 4.05 & 1.88 & & & \\
\hline Supnet1 & 0.844 & 0.119 & 5.55 & 1.46 & & & \\
\hline Supnet2 & 0.721 & 0.091 & 5.13 & 1.64 & & & \\
\hline Supnet3 & 0.858 & 0.127 & 4.97 & 1.44 & & & \\
\hline Disnet1 & 0.950 & 0.139 & 3.19 & 2.07 & & & \\
\hline Disnet2 & 0.934 & 0.133 & 3.09 & 2.01 & & & \\
\hline Disnet3 & 0.940 & 0.123 & 3.77 & 2.18 & & & \\
\hline $\begin{array}{l}\text { Supply } \\
\text { Sustainability }\end{array}$ & & & 5.20 & 1.62 & 0.752 & 0.862 & 0.68 \\
\hline Ecosus 2 & 0.994 & 0.444 & 4.96 & 1.74 & & & \\
\hline Ecosus 3 & 0.998 & 0.451 & 5.00 & 1.63 & & & \\
\hline Opersus1 & 0.948 & 0.297 & 5.65 & 1.39 & & & \\
\hline Supply Chain Performance & & & 4.40 & 1.81 & 0.878 & 0.912 & 0.67 \\
\hline Finperf3 & 0.994 & 0.253 & 4.27 & 1.77 & & & \\
\hline Finperf4 & 0.995 & 0.252 & 4.10 & 1.79 & & & \\
\hline Finperf5 & 0.992 & 0.253 & 3.95 & 1.88 & & & \\
\hline Markprf1 & 0.994 & 0.234 & 4.86 & 1.70 & & & \\
\hline Markprf2 & 0.990 & 0.225 & 4.80 & 1.72 & & & \\
\hline
\end{tabular}

Note: Loadings shown are after oblique rotation and Kaiser normalization.

Furthermore, discriminant validity is supported by two criteria in this study:

- The AVE of each latent construct should be higher than the construct's highest squared correlation with any other latent construct (Fornell and Lacker, 1981).

- An indicator's loading should be higher than all of its cross loadings (Hair et. al., 2011).

Table 2 displays that both criteria above for discriminant validity is supported. 
Table 2. Correlations among latent variables with sq. rts. of AVEs

\begin{tabular}{llllllc}
\hline Construct & 1 & 2 & 3 & 4 & 5 & 6 \\
\hline 1. Uncertainty & $\mathbf{0 . 8 1 7}$ & & & & & \\
2. Supply Chain Risks & 0.456 & $\mathbf{0 . 5 9 0}$ & & & & \\
3. Vulnerability & 0.349 & 0.467 & $\mathbf{0 . 7 2 0}$ & & & \\
4. Collaborative Planning System & 0.064 & -0.035 & -0.040 & $\mathbf{0 . 6 5 1}$ & & \\
5. Sustainability & -0.037 & -0.018 & 0.085 & 0.438 & $\mathbf{0 . 8 2 6}$ & \\
6. Supply Chain Performance & -0.063 & -0.196 & -0.050 & 0.469 & 0.498 & $\mathbf{0 . 8 2 1}$ \\
\hline
\end{tabular}

Note: Square roots of average variances extracted (AVEs) shown on diagonal

Concerning the results of the above statistical tests for reliability and validity, it is assumed that the factors of the variables are sufficiently valid and reliable to test hypotheses.

\subsection{Structural Model}

SEM is a collection of statistical techniques which examines a set of relationships between multiple independent and dependent variables simultaneously (Hair et al., 2006). The popularity of structural equation modeling (SEM) has grown out of the need to test complete theories and concepts (Rigdon, 1998). PLS-SEM is a causal modeling approach aimed at maximizing the explained variance of the dependent latent constructs. This is contrary to CB-SEM's objective of reproducing the theoretical covariance matrix, without focusing on explained variance (Hair et. al., 2011, pp. 139). It is an iterative algorithm that separately solves out the blocks of the measurement model and then, in a second step, estimates the path coefficients in the structural model (Vinzi et. al., 2010, pp. 48). Therefore, PLS-SEM is claimed to explain at best the residual variance of the latent variables and potentially, also of the manifest variables (indicators) in any regression run in the model (Fornell and Bookstein, 1982). Due to this reason, PLS Path Modeling is considered more as an exploratory approach than as a confirmatory one. Further, PLS is the most appropriate SEM approach when used with small sample sizes, non-normal and categorical data (Haenlein and Kaplan, 2014; Hair et. al., 2013). Basically, PLS combines principal components analysis and multivariate regression in order to define the dependent variable or variables included in the model (Edvardsson et. al., 2000). In order to reveal the reflective relationships between latent constructs and their indicators, PSL-SEM technique has been used in this research by utilizing WarpPLS 5.0 software. All items are standardized to zero mean and unit variance. To estimate the significance of path coefficients and item loadings, we use a bootstrapping approach, where 500 random samples of observations with replacements are generated from the original dataset (Efron and Tibshirani, 1993; Chin, 1998).

\subsection{Testing of Hypotheses}

The PLS-based structural equation modeling technique generates the path coefficients among the constructs. The significance of these coefficients was evaluated by using bootstrap procedure. In general, the bootstrap technique provides an estimate of the shape, spread and bias of the sampling distribution of the sampling distribution of a specific statistic. The procedure creates a large, pre-specified number of bootstrap samples (e.g., 5,000). PLS estimates the path model for each bootstrap sample. The obtained path model coefficients from a bootstrap distribution, which can be viewed as an approximation of the sampling distribution (Henseler et. al., 2009, pp. 305). Before parameter estimation of our conceptual model, we have increased the research sample to 500 by means of Bootstrapping method. By using WarpPLS software to test our conceptual model, following goodness of fit results have been obtained: Average path coefficient $\left(\mathrm{APC}=0.232^{* *}\right)$, Average R-squared (ARS = $\left.0.223^{* *}\right)$, and Average Variance Inflation Factor $\left(\mathrm{AVIF}=1.112^{* *}\right)$. In order for a structural model to be considered as powerful, APC and ARS should be significant at the level of $\mathrm{p}<0.01$ and that AVIF value should be lower than 5 (Kock, 2011).

Taking into consideration the direct relations in our proposed model, only uncertainty $(\beta=0.19, \mathrm{p}<0.01)$ has significant and direct effect on Supply Chain Vulnerability. Therefore, hypothesis $\mathrm{H}_{1 \mathrm{c}}$ has been supported. Furthermore, the relationships between Uncertainty and Supply Chain Performance and between Uncertainty and Collaborative Planning Systems demonstrated no significant effects. Hence, hypothesis $\mathrm{H}_{1 \mathrm{a}}$ and $\mathrm{H}_{2 \mathrm{~b}}$ have not been supported statistically.

Hypothesis $\mathrm{H}_{2 \mathrm{a}}$ and $\mathrm{H}_{2 \mathrm{c}}$ have examined the relationship between supply chain risks and supply chain performance and the relationship between supply chain risks and supply chain vulnerability, respectively. While supply chain risks have negative and direct effect on supply chain performance $(\beta=-0.17, p<0.01)$, the risks have a positive and direct effect on supply chain vulnerability $(\beta=0.41, \mathrm{p}<0.01)$. Therefore, hypotheses $\mathrm{H}_{2 \mathrm{a}}$ and $\mathrm{H}_{2 \mathrm{c}}$ have been accepted. However, the results for the relationship between supply chain risks and collaborative 
planning systems have revealed that the hypothesis $\mathrm{H}_{2 \mathrm{~b}}$ has been rejected.

Examination of the direct impact of both supply chain performance and collaborative planning systems on supply chain sustainability demonstrated to be statistically significant. Therefore, hypothesis $\mathrm{H}_{3}(\beta=0.37, \mathrm{p}<0.01)$ and $\mathrm{H}_{5}(\beta=0.29, \mathrm{p}<0.01)$ have been accepted. Nevertheless, the hypothesis $\mathrm{H}_{6}$ investigating the relationship between supply chain vulnerability and supply chain sustainability has been rejected.

Lastly, the results for the hypothesis $\left(\mathrm{H}_{4}\right)$ proposing a positive relationship between collaborative planning systems and supply chain performance in our conceptual model is supported $(\beta=0.47, \mathrm{p}<0.01)$.

The $\mathrm{R}^{2}$ values for the four dependent variables, i.e. SCP, collaborative planning systems, supply chain vulnerability and supply chain sustainability, are $0.26,0.04,0.27$, and 0.33 respecti vely. Vijayasarathy (2010) utilizes the $\mathrm{R}^{2}$ categorization of Cohen (1998) according to the effect sizes as small; 0.02, medium; 0.13 , and large; 0.26 . Hence, the results reveal explicitly that except collaborative planning systems, all the dependent variables have a large effect size. Table 3 displays the results of the hypotheses.

Table 3. Hypotheses results

\begin{tabular}{ll}
\hline Hypotheses & Results \\
\hline $\mathrm{H}_{1 \mathrm{a}}:$ Uncertainty - SC Performance & NS \\
$\mathrm{H}_{1 \mathrm{~b}}:$ Uncertainty - Collaborative Planning Systems & NS \\
$\mathrm{H}_{1 \mathrm{c}}:$ Uncertainty - SC Vulnerability & Supported \\
$\mathrm{H}_{2 \mathrm{a}}:$ SC Risks - SC Performance & Supported \\
$\mathrm{H}_{2 \mathrm{~b}}:$ SC Risks - Collaborative Planning Systems & NS \\
$\mathrm{H}_{2 \mathrm{c}}:$ SC Risks - SC Vulnerability & Supported \\
$\mathrm{H}_{3}:$ SC Performance - SC Sustainability & Supported \\
$\mathrm{H}_{4}:$ Collaborative Planning Systems - SC Performance & Supported \\
$\mathrm{H}_{5}:$ Collaborative Planning Systems - SC Sustainability & Supported \\
$\mathrm{H}_{6}:$ SC Vulnerability - SC Sustainability & NS \\
\hline
\end{tabular}

\section{Discussion and Conclusion}

Supply chain elements are constituted by many variables such as supply chain uncertainty, collaborative planning systems, supply chain vulnerability, supply chain performance, and supply chain sustainability. These variables display differences between various manufacturing enterprises. Hence, a conceptual model is proposed and empirically tested using PLS-SEM based on data collected from the enterprises in the automotive sector. This paper reports on the supply chain performance and sustainability study in the Turkish automotive industry, drawing on a sample of 213 manufacturing firms.

In this study, we aim to make a contribution to the literature by proposing a model, which examines the relationship between 3 main constructs -the supply chain performance, supply chain vulnerability and supply chain sustainability- and their antecedents. Towards this goal, we combined multiple approaches from to literature mainly focusing on the supply chain performance and its sustainability. We utilized PLS-SEM to test our hypothesis. Out of 10 hypothesis proposed, only 6 of them are found to be statistically significant. We have selected automotive sector as our focal due to the facility of gathering data and the need for disclosure of vulnerabilities in this sector. Supply chain performance and collaborative planning systems have both displayed positive relationships with supply chain sustainability as expected. However; surprisingly, we did not find any linkage between supply chain vulnerability and sustainability which is contrary to our expectations. The possible reason for this result might be that the other constructs i.e. collaborative planning systems and supply chain performance could lessen the impact of supply chain vulnerability on supply chain sustainability. Another interesting results which are derived from this study is that there have been no evidence found statistically supporting the hypotheses of the relationship between uncertainty and SC performance and the relationship between uncertainty and collaborative planning systems. Uncertainty and SC Risks have demonstrated positive and statistically significant relationship with vulnerability which is in good agreement with the findings in the literature.

Our findings support the fact that SC Risks is a major hindrance of supply chain performance and are also major driver for the rise in supply chain vulnerability. Managers should recognize and manage SC Risks in order to boost their supply chain performance and also their sustainability.

In summary, the overall findings of this study indicate that sustainable supply chain practices are an interesting field of research and these practices have a close linkage both with supply chain performance and collaborative planning systems. This study attempts to combine both supply chain performance, supply chain sustainability and its antecedents in a conceptual model.

Having a clear understanding of the exact nature of supply chain performance and sustainability will help firms 
to manage their risks and collaborative planning systems, to be followed by appropriate subsequent action plan.

\subsection{Limitations and Future Research}

Our results provide important explanations for supply chain sustainability and direct affecting constructs for sustainability and its antecedents in the automotive sector. The conceptual model, as a whole, except a few relationships between constructs has been supported empirically. As research limitations, following aspects should be mentioned. This study focuses on the automotive industry exclusively. Further research could be conducted for other industries like machinery, textile or electronics in order to test the general validity of the results. In addition, this study has been conducted in an emerging economy, and the results could change according to the culture, economy and sector. The welfare levels of the countries could have an impact on the results. Additionally, an international survey could give interesting insights regarding the degree of implementation in other countries. Last but not the least, increasing the sample size, broadening the geographic location and adding new constructs or moderators/mediators could improve the generalization of the findings.

\section{References}

Anderson, J. C., \& Gerbing, D. W. (1988). Structural equation modeling in practice: a review and recommend two-step approach. Psychological Bulletin, 103(3), 411-423. https://doi.org/10.1037/0033-2909.103.3.411

Bandaly, D. et. al. (2012). Supply chain risk management - I: Conceptualization, framework and planning process' Risk Management, 14, 249-271. https://doi.org/10.1057/rm.2012.7

Bavarsad, B. et. al. (2013). Study of Relationship Between Supply Chain Management Strategy With Logistics Performance And Organizational Performance. Interdisciplinary Journal of Contemporary Research in Business, 4(9), 1308-1317.

Blome, C., \& Schoenherr, T. (2011). Supply chain risk management in financial crises - a multiple case-study approach. International Journal of Production Economics, 134, 43-57. https://doi.org/10.1016/j.jpe.2011.01.002

Brown, T. A. (2006). Confirmatory Factor Analysis for Applied Research', Guilford Press, New York.

Cannon, J. P., \& Homburg, C. (2001). Buyer-Supplier Relationships and Customer Firm Costs. Journal of Marketing, 65, 29-43. https://doi.org/10.1509/jmkg.65.1.29.18136

Carter, C. R., \& Easton P. L. (2011). Sustainable supply chain management: evolution and future directions', International Journal of Physical Distribution \& Logistics Management, 41(1), 46-62. https://doi.org/10.1108/09600031111101420

Carter, C. R., \& Rogers, D. S. (2008). A framework of sustainable supply chain management: moving toward new theory. International Journal of Physical Distribution \& Logistics Management, 38(5), 360-387. https://doi.org/10.1108/09600030810882816

Chen, I. J., \& Paulraj, A. (2004). Towards a theory of supply chain management: the constructs and measurements. Journal of Operations Management, 22, 119-150. https://doi.org/10.1016/j.jom.2003.12.007

Cheung, Y. K. F., \& Rowlinson, S. (2011). Supply chain sustainability: a relationship management approach', International Journal of Managing Projects in Business, 4(3), 480-497. https://doi.org/10.1108/17538371111144184

Chin, W. W. (1998). Issues and opinion on structural equation modeling. MIS Quarterly, 22(1), 7-16.

Chin, W. W. (1998). The partial least squares approach to the structural equation modelling. In: Marcoulides, G.A. (Ed.), Modern Methods for Business Research. Lawrence Erlbaum Associates, Mahwah, 295-336.

Chopra, S., \& Sodhi, M. S. (2004). Managing risk to avoid supply-chain breakdown. MIT Sloan Manag. Rev., 46(1), 53-61.

Christopher, M., \& Peck, H. (2004). Building the resilient supply chain', International Journal of Logistics Management, 15(2), 1-13. https://doi.org/10.1108/09574090410700275

Cohen, J. (1998). Statistical Power Analysis for the Behavioral Sciences', $2^{\text {nd }}$ ed., Lawrence Erlbaum Associates, Hillsdale, New Jersey.

Cook, L. S., \& Heiser, D. R. (2010). The moderating effect of supply chain role on the relationship between supply chain practices and performance', International Journal of Physical Distribution \& Logistics Management, 41(2), 104-134. https://doi.org/10.1108/09600031111118521

Cucchiellla, F., \& Gastaildi, M. (2006). Risk management in supply chain: a real option approach. Journal of 
Manufacturing Technology Management, 17(6), 700-720. https://doi.org/10.1108/17410380610678756

Dowling, G., \& Staelin, R. (1994). A model of perceived risk and intended risk-handling activity. Journal of Consumer Research, 21, 119-134. https://doi.org/10.1086/209386

Edvarssson, B., Johnson, M. D., Gustafsson, A., \& Strandvik, T. (2000). The effects of satisfaction and loyalty on profits growth: products versus services. Total Quality Management, 11(7), 917-927. https://doi.org/10.1080/09544120050135461

Efron, B., \& Tibshirani, R. (1993). An Introduction to the Bootstrap. Chapman and Hall, Boa Raton. https://doi.org/10.1007/978-1-4899-4541-9

Etter, J. F., \& Perneger, T. V. (1997). Analysis of non-response bias in a mailed health survey. Journal of clinical epidemiology, 50(10), 1123-1128. https://doi.org/10.1016/S0895-4356(97)00166-2

Faisal, M. N., Banwet, D. K., \& Shankar, R. (2006). Supply chain risk mitigation: modeling the enablers. Business Process Management Journal, 12(4), 535-552. https://doi.org/10.1108/14637150610678113

Fornell, C., \& Bookstein, F. L. (1982). Two structural equation models: LISREL and PLS applied to consumer exit-voice theory. Journal of Marketing Research, 19, 440-452. https://doi.org/10.2307/3151718

Fornell, C., \& Larcker, D. F. (1981). Evaluating structural equations models with unobservable variables and measurement error. Journal of Marketing Research, 8(1), 39-50. https://doi.org/10.2307/3151312

Gunasekaran, A., \& Ngai, E. W. T. (2004). Information systems in supply chain integration and management. European Journal of Operational Research, 159(2), 269-295. https://doi.org/10.1016/j.ejor.2003.08.016

Haenlein, M., \& Kaplan, A. M. (2004). A beginner's guide to partial least squares analysis. Understanding Statistics,3(4), 283-297. https://doi.org/10.1207/s15328031us0304_4

Hair, J. F, Ringle, C. M., \& Sarstedt, M. (2011). PLS-SEM: Indeed a Silver Bullet', Journal of Marketing Theory and Practice, 19(2), 139-152. https://doi.org/10.2753/MTP1069-6679190202

Hair, J. F, Ringle, C. M., \& Sarstedt, M. (2013). Partial least squares structural modeling: rigorous applications, better results and higher acceptance. Long Range Planning, 46(1-2), 1-12. https://doi.org/10.1016/j.lrp.2013.01.001

Hair, J. F. J., Black, W. C., Babin, B. J., Anderson, R. E., \& Tatham, R. L. (2006). Multivariate data analysis. Pearson Education: New Jersey.

Hallikas, J., Virolainen, V. M., \& Tuominen, M. (2002). Risk analysis and assessment in network environments: a dyadic case study. International Journal of Production Economics, 78(1), 45-55. https://doi.org/10.1016/S0925-5273(01)00098-6

Helbing, D., Ammoser, H., \& Kühnert C. (2006). Disasters as extreme events and the importance of network interactions for disaster response management. In: Albeverio Sergio, Jentsch Volker, Kantz Holger, editors. Extreme events in nature and society, the frontiers collection. Berlin Heidelberg: Springer; 319-348. https://doi.org/10.1007/3-540-28611-X_15

Henseler, J., Ringle, C. M., \& Sinkovics, R. R. (2009). The use of partial least squares path modeling in international marketing, 20, 277-319.

Inman, R. A. et. al. (2011). Agile manufacturing: Relation to JIT, operational performance and firm performance. Journal of Operations Management, 29, 343-355. https://doi.org/10.1016/j.jom.2010.06.001

Jorekog, K. G., \& Sorbom, D. (1989). LISREL 7 Users Reference Guide, Scientific Software Inc., Chicago, IL.

Jüttner, U. (2005). Supply chain risk management. The International Journal of Logistics Management, 16(1), 120-141. https://doi.org/10.1108/09574090510617385

Kim, S. W. (2009). An investigation on the direct and indirect effect of supply chain integration on firm performance. International Journal of Production Economics, 119, 328-346. https://doi.org/10.1016/j.ijpe.2009.03.007

Kleijnen, M., Ruyter, K., \& Wetzels, M. (2007). An assessment of value creation in mobile service delivery and the moderating role of time consciousness. Journal of Retailing, 83(1), 33-46. https://doi.org/10.1016/j.jretai.2006.10.004

Kline, R. B. (2011). Principles and Practice of Structural Equation Modeling' $3^{\text {rd }}$ ed., Guilford Press, New York.

Kock, N. (2011). Using Warp PLS in e-collaboration studies: Descriptive statistics, Settings, and Key Analysis 
Results. Journal of e-Collaboration, 7(2), 1-18. https://doi.org/10.4018/jec.2011040101

Kocoglu, I. et. al. (2011). The effect of supply chain integration on information sharing: Enhancing the supply chain performance. Procedia Social and Behavioral Sciences, 24, 1630-1649. https://doi.org/10.1016/j.sbspro.2011.09.016

Krysiak, F. C. (2009). Risk Management as a Tool for Sustainability. Journal of Business Ethics, 85, 483-492. https://doi.org/10.1007/s10551-009-0217-7

Kumar, C. G., \& Nambirajan, T. (2014). Does Supply Chain Performance Mediates The Relationship Between Critical Supply Chain Management Components And Organizational Performance? Delhi Business Review, 15(1), 67-81.

$\mathrm{Li}$, G. et. al. (2008). The impact of IT implementation on supply chain integration and performance. International Journal of Production Economics, 120, 125-138. https://doi.org/10.1016/j.ijpe.2008.07.017

$\mathrm{Li}$, S. et. al. (2006). The impact of supply chain management practices on competitive advantage and organizational performance. The International Journal of Management Science, 34, 107-124. https://doi.org/10.1016/j.omega.2004.08.002

Lin, I., \& Schaeffer, N. C. (1995). Using survey participants to estimate the impact of nonparticipation. Public Opinion Quarterly, 59(2), 236-258. https://doi.org/10.1086/269471

Manuj, I., \& Mentzer, J. T. (2008). Global supply chain risk management. J. Bus. Logist., 29(1), 133-155. https://doi.org/10.1002/j.2158-1592.2008.tb00072.x

Menachemi, N. (2010). Assessing response bias in a web survey at a university faculty. Evaluation and Research in Education, 24(1), 5-15. https://doi.org/10.1080/09500790.2010.526205

Mentzer, J. T. (2001). Defining Supply Chain Management. Journal of Business Logistics, 22(2), 1-26. https://doi.org/10.1002/j.2158-1592.2001.tb00001.x

Merschmann, U., \& Thonemann, U. W. (2011). Supply chain flexibility, uncertainty and firm performance: An empirical analysis of German manufacturing firms. International Journal of Production Economics, 130, 43-53. https://doi.org/10.1016/j.ijpe.2010.10.013

Min, S., \& Mentzer, J. T. (2004). Developing and Measuring Supply Chain Management Concepts. Journal of Business Logistics, 25(1), 63-99. https://doi.org/10.1002/j.2158-1592.2004.tb00170.x

Norrman, A., \& Jansson, U. (2004). Ericsson's proactive supply chain risk management approach after a serious sub - supplier accident. International Journal of Physical Distribution and Logistics Management, 34(5), 434-456. https://doi.org/10.1108/09600030410545463

Nunnally, J. C., \& Bernstein, I. H. (1994). Psychometric Theory', $3^{\text {rd }}$ ed., McGraw-Hill, New York.

Podsakoff, P. M., MacKenzie, S. B., Lee, J. Y., \& Podsakoff, N. P. (2003). Common method biases in behavioral research: A critical review of the literature and recommended remedies. Journal of Applied Psychology, 88(5), 879-903. https://doi.org/10.1037/0021-9010.88.5.879

Power, D. J., Sohal, A. S., \& Rahman, S. U. (2001). Critical success factors in agile supply chain management-An empirical study', International Journal of Physical Distribution and Logistics Management, 31(4), 247-265. https://doi.org/10.1108/09600030110394923

Qrunfleh, S., \&Tarafdar, M. (2013). Lean and agile supply chain strategies and supply chain responsiveness: the role of strategic supplier partnership and postponement. Supply Chain Management: An International Journal, 18(6), 571-582. https://doi.org/10.1108/SCM-01-2013-0015

Qrunfleh, S., Tarafdar, M., \& Ragu - Nathan, T. S. (2012). Examining alignment between supplier management practices and information systems strategy. Benchmarking: An International Journal, 19, 604-617. https://doi.org/10.1108/14635771211258034

Reio, T. G. (2010). The threat of common method variance bias to theory building. Human Resource Development Review, 9(4), 405-411. https://doi.org/10.1177/1534484310380331

Rezaei, S., \& Ghodsi, S. S. (2014). Does value matters in playing online game? An empirical study among massively multiplayer online role-gaming games (MMORPGs). Computers in Human Behavior, 35, 252-266. https://doi.org/10.1016/j.chb.2014.03.002

Rigdon, E. E. (1998). Structural equations modeling”, in Marcoulides, G.A. (Ed.), Modern Methods for Business Research, Lawrence-Erlbaum Associates, Mahwah, NJ, 251-294. 
Schaltegger, S., \& Burritt, R. (2014). Measuring and managing sustainability performance of supply chains Review and sustainability supply chain management framework. Supply Chain Management: An International Journal, 19(3), 232-241. https://doi.org/10.1108/SCM-02-2014-0061

Seuring, S., \& Müller, M. (2008). From a literature review to a conceptual framework for sustainable supply chain management. Journal of Cleaner Production, 16(15), 1699-1710. https://doi.org/10.1016/j.jclepro.2008.04.020

Sinha, P. R., Whitman, L. E., \& Malzahn, D. (2004). Methodology to mitigate supplier risk in an aerospace supply chain. Supply Chain Management: International Journal, 9(2), 154-168. https://doi.org/10.1108/13598540410527051

Spector, P. E. (2006). Method variance in organizational research truth or urban legend? Organ. Res. Methods, 9(2), 221-232. https://doi.org/10.1177/1094428105284955

Stauffer, D. (2003). Supply Chain Risk: Deal With It. Harward Business School-Working Knowledge, 1-4.

Svensson, G. (2000). A conceptual analysis for the framework for the analysis of vulnerability in supply chains', International Journal of Physical Distribution \& Logistics Management, 30(9), 731-749. https://doi.org/10.1108/09600030010351444

Tang, C. S. (2006). Perspectives in supply chain risk management. International Journal of Production Economics, 103(2), 451-488. https://doi.org/10.1016/j.ijpe.2005.12.006

Tang, C. S. (2006). Robust strategies for mitigating supply chain disruptions. International Journal of Logistics Research and Applications: A Leading Journal of Supply Chain Management, 9(1), 33-45. https://doi.org/10.1080/13675560500405584

Thompson, S. A., Loveland, J. M., \& Fombelle, P. W. (2014). Thematic discrepancy analysis: a method to gain insights into lurkers and test for non-response bias. Journal of Interactive Marketing, 28(1), 55-67. https://doi.org/10.1016/j.intmar.2013.06.001

Thun, J. H., \& Hoenig, D. (2011). An empirical analysis of supply chain risk management in the German automotive industry. International Journal of Production Economics, 131, 242-249. https://doi.org/10.1016/j.ijpe.2009.10.010

Trkman, P., \& McCormack, K. (2009). Supply chain risk in turbulent environments-A conceptual model for managing supply chain network risk', International Journal of Production Economics, 119, 247-258. https://doi.org/10.1016/j.ijpe.2009.03.002

Vanichchinchai, A., \& Igel, B. (2011). The impact of total quality management on supply chain management and firm's supply performance. International Journal of Production Research, 49(11), 3405-3424. https://doi.org/10.1080/00207543.2010.492805

Vijayasarathy, L. R. (2010). Supply integration: An investigation of its multi-dimensionality and relational antecedents. International Journal of Production Economics, 124, 489-505. https://doi.org/10.1016/j.jpe.2010.01.010

Vinzi, V. E. et. al. (2010). Handbook of Partial Least Squares', Springer, Berlin. https://doi.org/10.1007/978-3-540-32827-8

Wagner, S. M., \& Bode, C. (2006). An empirical investigation into supply chain vulnerability. Journal of Purchasing \& Supply Management, 12, 301-312. https://doi.org/10.1016/j.pursup.2007.01.004

Wagner, S. M., \& Bode, C. (2008). An empirical examination of supply chain performance along several dimensions of risk. Journal of Business Logistics, 29, 307-325. https://doi.org/10.1002/j.2158-1592.2008.tb00081.x

Wang, Z., \& Sarkis, J. (2013). Investigating the relationship of sustainable supply chain management with corporate financial performance. International Journal of Productivity and Performance Management, 63(8), 871-888. https://doi.org/10.1108/IJPPM-03-2013-0033

Wieland, A., \& Wallenburg, C. M. (2012). Dealing with supply chain risks- Linking risk management practices and strategies to performance', International Journal of Physical Distribution \& Logistics Management, 42(10), 887-905. https://doi.org/10.1108/09600031211281411

Williams, L. J., \& Brown, B. K. (1994). Method variance in organizational behavior and human resources research: effects on correlations, path coefficients, and hypothesis testing. Organizational Behavior and 
Human Decision Processes, 57(2), 185-209. https://doi.org/10.1006/obhd.1994.1011

Wu, T., \& Blackhurst, J. (2009). Managing Supply Chain Risk and Vulnerability: Tools and Methods for Supply Chain Decision Makers', Springer, New York. https://doi.org/10.1007/978-1-84882-634-2

Zailani, S. et. al. (2012). Sustainable supply chain management (SSCM) in Malaysia: A survey', International Journal of Production Economics, 140, 330-340. https://doi.org/10.1016/j.ijpe.2012.02.008

Zsidisin, G. A., Ellram, L. M., Carter, J. R., \& Cavinato, J. L. (2004). An analysis of supply risk assessment techniques. International Journal of Physical Distribution \& Logistics Management, 34(5), 397-413. https://doi.org/10.1108/09600030410545445

\section{Copyrights}

Copyright for this article is retained by the author(s), with first publication rights granted to the journal.

This is an open-access article distributed under the terms and conditions of the Creative Commons Attribution license (http://creativecommons.org/licenses/by/4.0/). 